\title{
Technical Note: On the use of nudging for aerosol-climate model intercomparison studies
}

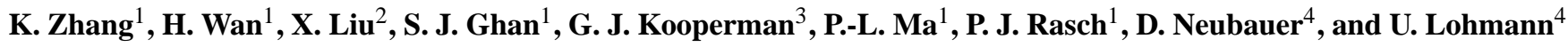 \\ ${ }^{1}$ Pacific Northwest National Laboratory, Richland, Washington, USA \\ ${ }^{2}$ University of Wyoming, Laramie, Wyoming, USA \\ ${ }^{3}$ Scripps Institution of Oceanography, University of California, San Diego, La Jolla, California, USA \\ ${ }^{4}$ Institute of Atmospheric and Climate Science, ETH Zurich, Zurich, Switzerland \\ Correspondence to: K. Zhang (kai.zhang@pnnl.gov)
}

Received: 31 March 2014 - Published in Atmos. Chem. Phys. Discuss.: 24 April 2014

Revised: 13 July 2014 - Accepted: 17 July 2014 - Published: 26 August 2014

\begin{abstract}
Nudging as an assimilation technique has seen increased use in recent years in the development and evaluation of climate models. Constraining the simulated wind and temperature fields using global weather reanalysis facilitates more straightforward comparison between simulation and observation, and reduces uncertainties associated with natural variabilities of the large-scale circulation. On the other hand, the forcing introduced by nudging can be strong enough to change the basic characteristics of the model climate. In the paper we show that for the Community Atmosphere Model version 5 (CAM5), due to the systematic temperature bias in the standard model and the sensitivity of simulated ice formation to anthropogenic aerosol concentration, nudging towards reanalysis results in substantial reductions in the ice cloud amount and the impact of anthropogenic aerosols on long-wave cloud forcing.

In order to reduce discrepancies between the nudged and unconstrained simulations, and meanwhile take the advantages of nudging, two alternative experimentation methods are evaluated. The first one constrains only the horizontal winds. The second method nudges both winds and temperature, but replaces the long-term climatology of the reanalysis by that of the model. Results show that both methods lead to substantially improved agreement with the freerunning model in terms of the top-of-atmosphere radiation budget and cloud ice amount. The wind-only nudging is more convenient to apply, and provides higher correlations of the wind fields, geopotential height and specific humidity between simulation and reanalysis. Results from both CAM5 and a second aerosol-climate model ECHAM6-HAM2 also
\end{abstract}

indicate that compared to the wind-and-temperature nudging, constraining only winds leads to better agreement with the free-running model in terms of the estimated shortwave cloud forcing and the simulated convective activities. This suggests nudging the horizontal winds but not temperature is a good strategy for the investigation of aerosol indirect effects since it provides well-constrained meteorology without strongly perturbing the model's mean climate.

\section{Introduction}

Nudging (also called Newtonian relaxation) of meteorological fields towards estimates from weather analyses has been used in various studies concerning climate model development and evaluation (e.g., Jeuken et al., 1996; Feichter and Lohmann, 1999; Machenhauer and Kirchner, 2000; Ghan et al., 2001; Hauglustaine et al., 2004; Kerkweg et al., 2006; Schmidt et al., 2006; Telford et al., 2008; Kooperman et al., 2012). This technique introduces extra terms into the equations that govern the evolution of temperature, horizontal winds (or equivalently, vorticity and divergence) and sometimes mass fields, to nudge them towards observed values. Nudging can be useful when developing and evaluating physical parameterizations and chemistry modules (e.g., van Aalst et al., 2004; Stier et al., 2005; Lohmann and Hoose, 2009; Jöckel et al., 2010; Zhang et al., 2012; Ma et al., 2014), because it strongly constrains some terms (e.g. advection) to be driven by observed meteorological events, meanwhile allows other terms (processes) described 
by physical parameterizations to evolve freely and drive the evolution of variables that are not being nudged. If the unconstrained terms approximate atmospheric processes reasonably, the resulting simulations should produce modeled features that can be compared to observation for specific weather episodes (Feichter and Lohmann, 1999; Dentener et al., 1999; Coindreau et al., 2007; Schulz et al., 2009; Roelofs et al., 2010). Because the meteorological features are strongly constrained, nudging eliminates one source of model variability, reduces error and uncertainty in other terms, and thus facilitates detection of signatures of changes in process representations (parameterizations) in simulations that might otherwise require multiple decades of simulation time in order to clearly discriminate between signal and noise (Lohmann and Hoose, 2009; Lohmann and Ferrachat, 2010; Kooperman et al., 2012). Because of these benefits, the AeroCom aerosol-climate model intercomparison initiative (http://aerocom.met.no/) explicitly requires nudged simulations for several projects of its Phase III activities on assessing the aerosol indirect effect (https://wiki.met.no/aerocom/ indirect).

The present paper is motivated by an AeroCom Phase III intercomparison that focuses on aerosol indirect effects through ice clouds (hereafter referred to as ice-AIE). The original experimental design required nudging both temperature and horizontal winds towards the ERA-Interim (Dee et al., 2011) reanalysis. When simulations were performed using the Community Atmosphere Model version 5 (CAM5, Neale et al., 2010), it was noticed that the top-of-atmosphere (TOA) radiation budget was substantially different from that of the unconstrained model. This implies the aerosol indirect effects estimated from the AeroCom ice-AIE experiments would differ from the standard (unconstrained) CAM5 estimates, and thus answers reported with this methodology would not be an accurate characterization of CAM5 behavior. Conducting the ice-AIE experiments without nudging, on the other hand, would cause difficulties in the evaluation against observation, and hinder the intercomparison with other models. In this work we carried out a number of sensitivity experiments to identify the cause of discrepancies between the nudged and unconstrained simulations. We also explored alternative nudging strategies that may help ensure resemblance between the simulated and observed large-scale circulation, and meanwhile avoid strongly perturbing the model's radiation balance. To demonstrate that the method preferred for CAM5 could also benefit other models, a subset of the sensitivity experiments were repeated using a second aerosol-climate model ECHAM6-HAM2 (Stier et al., 2005; Zhang et al., 2012) which, in terms of the model formulation, shares very little in common with CAM5.

The remainder of the paper is organized as follows: Sect. 2 briefly introduces the two models and describes the simulations. Section 3 investigates the impact of nudging on ice clouds and the TOA radiation budget in CAM5. Section 4 evaluates two alternative nudging strategies. Sect. 5 dis-

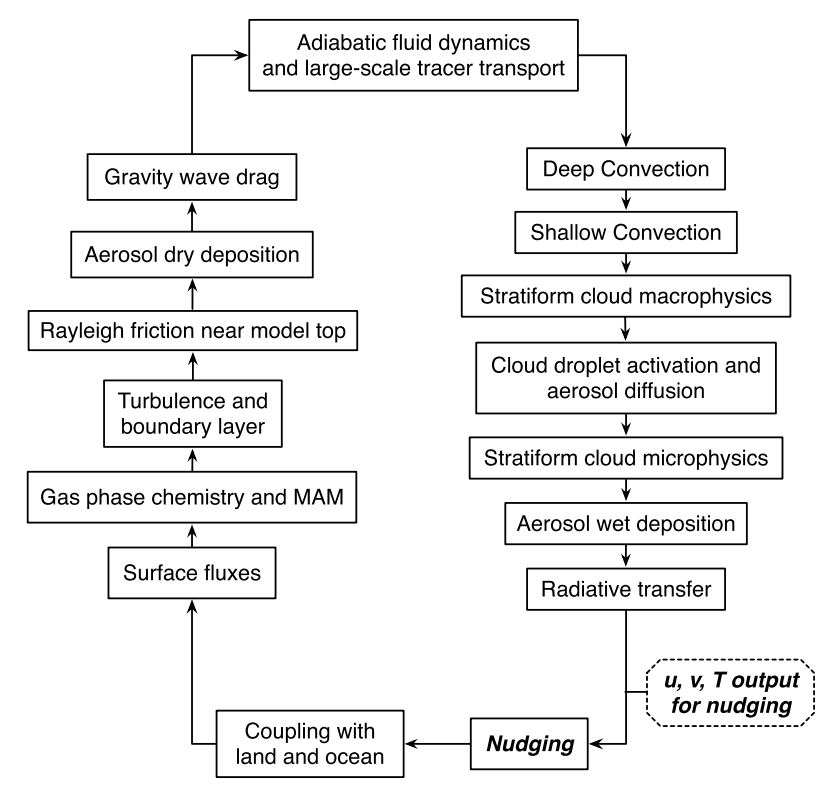

Figure 1. Flowchart showing the implementation of nudging in the computing sequence of the CAM5 model.

cusses the ECHAM6-HAM2 results. Conclusions are drawn in Sect. 6.

\section{Models and simulations}

\subsection{A brief overview of CAM5}

In this study, we use CAM5.1 with the finite volume dynamical core (Lin, 2004) at $1.9^{\circ}$ latitude $\times 2.5^{\circ}$ longitude resolution with 30 layers in the vertical, and a time step length of $30 \mathrm{~min}$ for the physics parameterizations. The modal aerosol module MAM3 (Liu et al., 2012) represents the tropospheric aerosol life cycle, including various emission and formation mechanisms, microphysical processes, and removal mechanisms. The simulated aerosols are composed of sulfate, black carbon, primary and secondary organic aerosols, sea salt, and mineral dust.

The stratiform cloud microphysics in CAM5.1 is represented by a two-moment parameterization (Morrison and Gettelman, 2008; Gettelman et al., 2008, 2010). Aerosols can directly affect the formation and properties of stratiform clouds by acting as cloud condensation nuclei (CCN) and ice nuclei (IN). Particles with mixed compositions that have high hygroscopicity provide sources for $\mathrm{CCN}$, while dustcontaining particles can act as IN. Ice particles can also form through the homogeneous freezing of aqueous sulfate aerosol solution. The ice nucleation parameterizations are described in Liu and Penner (2005); Liu et al. (2007) and Gettelman et al. (2010). 
Representation of deep and shallow convection in CAM5 follows the work of Zhang and McFarlane (1995) and Park and Bretherton (2009), respectively. For the Zhang and McFarlane (1995) deep convection, although a two-moment microphysics scheme has been developed and evaluated (Song and Zhang, 2011; Song et al., 2012; Lim et al., 2014), it is not included in the model version used in this study. Moist turbulence is represented by the parameterization of Bretherton and Park (2009). Shortwave and long-wave radiative transfer calculations are performed using the RRTMG (Rapid Radiative Transfer Model for General circulation model applications) code (Iacono et al., 2008; Mlawer et al., 1997). Further details of the model formulation are described in Neale et al. (2010).

\subsection{Nudging}

The implementation of nudging in CAM5 follows the work of Kooperman et al. (2012). A tendency term of the form

$-\frac{X_{\mathrm{M}}-X_{\mathrm{P}}}{\tau_{X}}$

is added to the prognostic equation of variable $X$ where $X$ stands for dry static energy (as a substitute for temperature) or horizontal winds. Subscript M indicates the model predicted value. Subscript $P$ refers to the prescribed value, which can come from either a global weather reanalysis or a baseline CAM5 simulation performed without nudging. $\tau_{X}$ denotes the nudging time scale which can be variable dependent. In the study of Kooperman et al. (2012), a $6 \mathrm{~h}$ relaxation time was used for both temperature and winds, and the model was nudged to the 6 hourly model output from a baseline CAM5 simulation.

Technically, the nudging term (Eq. 1) in CAM5 is applied as part of the "physics" tendency. It is used to update the model state variables after the moist processes and radiative transfer, and before the coupling of the atmosphere model with land and ocean (Fig. 1). For simulations that are nudged towards CAM5's own meteorology, the prior baseline simulation writes out the wind and temperature fields at the same location (dashed box in Fig. 1). Our experience revealed the location in the computation sequence is important, because choosing to archive the data at a location that differs from the point where nudging is applied can introduce an unintended forcing term that causes systematic differences in the simulated clouds, precipitation, and energy budget. This issue highlights the delicate balance of terms in the evolution equations, and the importance of a careful choice in the strategy used for nudging.

Later in the paper we will evaluate simulations that were nudged either to the ERA-Interim reanalysis or to a CAM5 baseline simulation, and assess the impact of the temperature relaxation time $\tau_{T}$. In addition, we will discuss a nudging strategy that replaces formula (Eq. 1) by

$-\frac{X_{\mathrm{M}}^{\prime}-X_{\mathrm{P}}^{\prime}}{\tau_{X}}$,

where $X^{\prime}$ denotes the anomaly of $X$ with respect to its monthly mean climatology $\bar{X}$, i.e.,

$X_{M}^{\prime}=X_{M}-\bar{X}_{M}$,

$X_{P}^{\prime}=X_{P}-\bar{X}_{P}$.

The motivation for the anomaly nudging is that the original formula (Eq. 1) can be expressed as

$$
\begin{aligned}
-\frac{X_{M}-X_{P}}{\tau_{X}} & =-\frac{\left(\bar{X}_{M}+X_{M}^{\prime}\right)-\left(\bar{X}_{P}+X_{P}^{\prime}\right)}{\tau_{X}} \\
& =-\frac{\left(X_{M}^{\prime}-X_{P}^{\prime}\right)}{\tau_{X}}-\frac{\left(\bar{X}_{M}-\bar{X}_{P}\right)}{\tau_{X}} .
\end{aligned}
$$

When the model fields are nudged towards reanalysis, the first term on the right-hand side of Eq. (6) can be interpreted as a forcing term that relaxes the synoptic perturbations towards the observed episodes, which is the actual purpose of using nudging in the ice-AIE experiments. The second term forces the model mean state towards the observed mean, correcting the biases in the model climatology. This is not intended by the AeroCom ice-AIE intercomparison.

The anomaly nudging Eq. (2) can be re-written as

$-\frac{X_{M}^{\prime}-X_{P}^{\prime}}{\tau_{X}}=-\frac{X_{M}-X_{P}^{*}}{\tau_{X}}$

where

$X_{\mathrm{P}}^{*}=X_{\mathrm{P}}-\bar{X}_{\mathrm{P}}+\bar{X}_{\mathrm{M}}$.

This means the anomaly nudging can be implemented using a term that appears identical to expression (Eq. 1) but with $X_{\mathrm{P}}$ replaced by $X_{\mathrm{P}}^{*}$. It thus requires only a pre-processing of the reanalysis data, without any change to the model source code.

\subsection{CAM5 simulations}

Following the protocol of the AeroCom III ice-AIE intercomparison, we carried out AMIP (Atmospheric Model Intercomparison Project, Gates et al., 1999) simulations for the years 2006 through 2010 after a 3-month spin-up from October to December 2005. Concentrations of the greenhouse gases were set at the year 2000 observed values. For the anthropogenic and biomass burning emissions of aerosols and precursor gases, the year 2000 and 1850 fluxes of Lamarque et al. (2010) were used for the present-day (PD) and preindustrial (PI) simulations, respectively. It is worth clarifying that as intended by AeroCom, the PI simulations were conducted using the same greenhouse gas concentrations, sea surface temperature, and sea ice extent as in the PD simulations. The PD-PI differences are thus solely attributable to changes in the emission of aerosols and their precursor gases. 
Table 1. List of CAM5 simulations. $\tau_{U}, \tau_{V}, \tau_{T}$ are the relaxation time scales for zonal wind, meridional wind, and temperature, respectively. TL refers to the vertical levels (given as indices counting from model top) on which temperature nudging was applied. The interface between model layers 15 and 16 roughly corresponds to the $300 \mathrm{hPa}$ pressure level. Details of the experimental setup are described in Sect. 2.3.

\begin{tabular}{|c|c|c|c|c|c|c|}
\hline Simulation & $\tau_{U}$ & $\tau_{V}$ & $\tau_{T}$ & $\mathrm{TL}$ & Description & Cf. Section \\
\hline CLIM & - & - & - & - & reference simulation without nudging & Sects. 3 and 4 \\
\hline NDG_CLIM_UVT & $6 \mathrm{~h}$ & $6 \mathrm{~h}$ & $6 \mathrm{~h}$ & all & nudged towards the present-day CLIM simulation & Sects. 3 and 4 \\
\hline NDG_ERA_UVT & $6 \mathrm{~h}$ & $6 \mathrm{~h}$ & $6 \mathrm{~h}$ & all & nudged towards ERA-Interim reanalysis & Sect. 3 \\
\hline NDG_ERA_T1D & $6 \mathrm{~h}$ & $6 \mathrm{~h}$ & 1 day & all & nudged towards ERA-Interim reanalysis & Sect. 3 \\
\hline NDG_ERA_T4D & $6 \mathrm{~h}$ & $6 \mathrm{~h}$ & 4 days & all & nudged towards ERA-Interim reanalysis & Sect. 3 \\
\hline NDG_ERA_T16D & $6 \mathrm{~h}$ & $6 \mathrm{~h}$ & 16 days & all & nudged towards ERA-Interim reanalysis & Sect. 3 \\
\hline NDG_ERA_T64D & $6 \mathrm{~h}$ & $6 \mathrm{~h}$ & 64 days & all & nudged towards ERA-Interim reanalysis & Sect. 3 \\
\hline NDG_ERA_UPPER & $6 \mathrm{~h}$ & $6 \mathrm{~h}$ & $6 \mathrm{~h}$ & $1-15$ & nudged towards ERA-Interim reanalysis & Sect. 3 \\
\hline NDG_ERA_LOWER & $6 \mathrm{~h}$ & $6 \mathrm{~h}$ & $6 \mathrm{~h}$ & $16-30$ & nudged towards ERA-Interim reanalysis & Sect. 3 \\
\hline NDG_ERA_UV & $6 \mathrm{~h}$ & $6 \mathrm{~h}$ & - & - & nudged towards ERA-Interim reanalysis & Sect. 4 \\
\hline NDG_ERA_UVTa & $6 \mathrm{~h}$ & $6 \mathrm{~h}$ & $6 \mathrm{~h}$ & all & anomaly nudging using Eqs. (7) and (8) & Sect. 4 \\
\hline
\end{tabular}

In order to provide a reference for the model's characteristic climatology under the standard configuration, we performed a pair of PD and PI simulations with the free-running CAM (i.e., without nudging, referred to as the "CLIM" simulations in the remainder of the paper. cf. Table 1). A second pair of integrations followed the original ice-AIE protocol, in which both temperature and horizontal winds were nudged to the ERA-Interim reanalysis with a $6 \mathrm{~h}$ relaxation time ("NDG_ERA_UVT"). To identify the cause of discrepancies between these two sets of simulations, we conducted simulations with $u, v$, and $T$ nudged towards 6 hourly output from the PD CLIM case ("NDG_CLIM_UVT"). Several additional sensitivity simulations were conducted where the ERA-Interim reanalysis was used to prescribe the meteorology, but the value of $\tau_{T}$ was varied (e.g., "NDG_ERA_T1D"), or only part of the vertical domain was nudged ("NDG_ERA_UPPER" and "NDG_ERA_LOWER"). The wind-only nudging ("NDG_ERA_UV") and anomaly nudging ("NDG_ERA_UVTa") were also applied and tested. A summary of the sensitivity simulations is provided in Table 1.

\subsection{ECHAM6-HAM2 simulations}

Simulations were also performed using a different model. The global aerosol-climate model ECHAM-HAM is developed by a consortium composed of ETH Zurich (Switzerland), Max Planck Institute for Meteorology (Germany), Forschungszentrum Jülich (Germany), University of Oxford (UK), and the Finnish Meteorological Institute (Finland), and is managed by the Center for Climate Systems Modeling (C2SM) at ETH Zurich. We used here the most recent version ECHAM6-HAM2.

Like MAM3 in CAM5, the aerosol module HAM (Stier et al., 2005; Zhang et al., 2012) uses the modal approach to describe aerosol size distribution, but the number and definition of modes, as well as the parameterizations of aerosol related physical and chemical processes, are generally different. Details of the model formulation and performance can be found in Stier et al. (2005), Zhang et al. (2012) and references therein.

The atmosphere model ECHAM6 (Giorgetta et al., 2012; Stevens et al., 2013) has a spectral transform dynamical core with finite-difference vertical discretization (Simmons et al., 1989), and uses finite-volume methods for the resolved-scale tracer transport (Lin and Rood, 1996).

Cumulus convection is represented by the parameterization of Tiedtke (1989) with modifications by Nordeng (1994) for deep convection. Turbulent mixing of momentum, heat, moisture and tracers is parameterized with the eddy-diffusivity scheme of Brinkop and Roeckner (1995). Shortwave and long-wave radiative transfer are handled by RRTMG (Iacono et al., 2008).

The aerosol concentrations predicted by HAM are coupled to a two-moment cloud microphysics scheme that includes prognostic equations for the cloud droplet and ice crystal number concentrations (Lohmann et al., 2007; Lohmann and Hoose, 2009). The representation of ice nucleation follows Lohmann et al. (2007). Homogeneous ice nucleation in cirrus clouds with temperature below $-35 \mathrm{C}^{\circ}$ is parameterized as in Kärcher and Lohmann (2002) and Lohmann and Kärcher (2002).

Nudging in ECHAM is implemented in the same form as expression (1), with $X$ being vorticity, divergence, temperature, or surface pressure. The nudging tendency is applied after model dynamics, in spectral space. In the standard setup, the nudging time scales are $6 \mathrm{~h}$ for vorticity, $48 \mathrm{~h}$ for divergence, $24 \mathrm{~h}$ for temperature, and $24 \mathrm{~h}$ for surface pressure (Lohmann and Hoose, 2009). 
The simulations discussed later in Sect. 2.4 were performed at T63 resolution (approximately $1.9^{\circ}$ latitude $\times 1.9^{\circ}$ longitude) with 31 layers in the vertical. Most of the sensitivity experiments listed in Table 1 were repeated using ECHAM6-HAM2. However, since the purpose of discussing results from a second model is to further compare the original AeroCom experimental design and our new recommendation, for ECHAM6-HAM2 we focus mainly on three configurations: without nudging ("CLIM"), with the default nudging ("NDG_ERA_VDT"), and with the vorticity-divergence nudging ("NDG_ERA_VD”). In Sect. 5 we will also briefly discuss a series of simulations in which the temperature relaxation time scale was varied. For a convenient comparison with CAM5, we will refer to the NDG_ERA_VD configuration as the "wind-only" nudging. Furthermore, it is to be understood that surface pressure is always constrained with a $48 \mathrm{~h}$ time scale in the nudged ECHAM6-HAM2 simulations.

\section{Temperature bias and ice nucleation in CAM5}

For the CAM5 model, Kooperman et al. (2012) noted that nudging towards the ERA-Interim reanalysis led to nonnegligible changes in the simulated hydrological cycle, e.g., in the global mean precipitation rate and cloud water content. Our ice-AIE experiments indicate that nudging also leads to changes in the estimated aerosol indirect effects. Figure 2 shows the globally averaged 5 yr mean PD-PI differences in several quantities related to the TOA radiation budget. To facilitate a quantitative comparison, results from the nudged simulations have been normalized by the corresponding values derived from the CLIM simulations. (The original data can be found in Table A2.) Aerosol-induced changes in the TOA net shortwave radiation flux ( $\triangle \mathrm{FSNT}$ ) and shortwave cloud forcing $(\triangle \mathrm{SWCF})$ are reasonably similar in the free-running and nudged simulations, with discrepancies being less than $25 \%$ (Fig. 2a). For the long-wave radiation flux $(\triangle \mathrm{FLNT})$ and cloud forcing $(\triangle \mathrm{LWCF})$, however, results from the ERA-nudged simulations are about a factor of 4 smaller (Fig. 2b).

To understand this difference, we included in Fig. 2 the simulations that were nudged towards CAM5's baseline simulation (blue bars). This setup did not produce small $\triangle F L N T$ and $\triangle$ LWCF. Rather, the PD-PI differences are slightly larger than in the free-running model (consistent with results of Kooperman et al., 2012), possibly because nudging the PD and PI simulations towards the same PD CLIM meteorology suppresses negative feedbacks from the large-scale circulation. The similarity between the nudged-to-baseline and free-running simulations, and the large contrast between them and the nudged-to-reanalysis simulations, suggest that the discrepancies in the climatology between CLIM and reanalysis probably play an important role here.
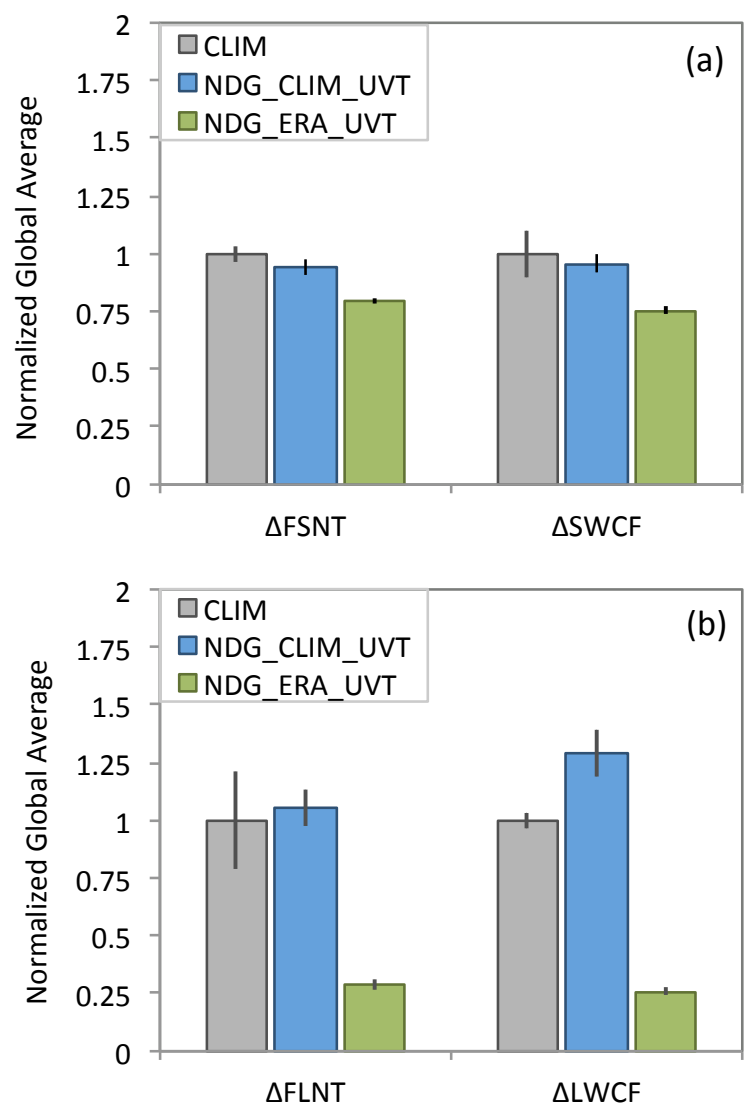

Figure 2. Normalized global mean $5 \mathrm{yr}$ mean CAM5 PD-PI differences $(\Delta)$ in the (a) TOA net shortwave radiation flux (FSNT) and shortwave cloud forcing (SWCF), and (b) TOA net long-wave radiation flux (FLNT) and long-wave cloud forcing (LWCF). The thin vertical line associated to each bar indicates the standard deviation of the annual average. Results from the nudges simulations (NDG_CLIM_UVT and NDG_ERA_UVT) are normalized by the corresponding $5 \mathrm{yr}$ average PD-PI differences from the unconstrained (CLIM) simulations. Details of the experimental setup are explained in Sect. 2.3 and Table 1.

Further investigation revealed that the differences in radiation budget are attributable to the temperature changes introduced by nudging towards reanalysis. Compared to the ERA reanalysis, the standard CAM5 model has a general cold bias at locations where there is appreciable amount of cloud ice, as can be seen from the zonal and annual mean temperature differences in Fig. 3a. The same features are revealed in a comparison with the NCEP (Kanamitsu et al., 2002) and MERRA (Rienecker et al., 2011) reanalyses (Fig. 3b and c). Nudging towards reanalysis introduces a correction term in the thermodynamic equation (cf. Eq. 6, second term) and makes the simulated atmosphere warmer in these regions. The higher temperature, and the associated lower relative humidity, significantly reduce the frequency of occurrence of homogeneous ice nucleation (Fig. 4), causing considerable decreases in ice crystal concentration in the upper 

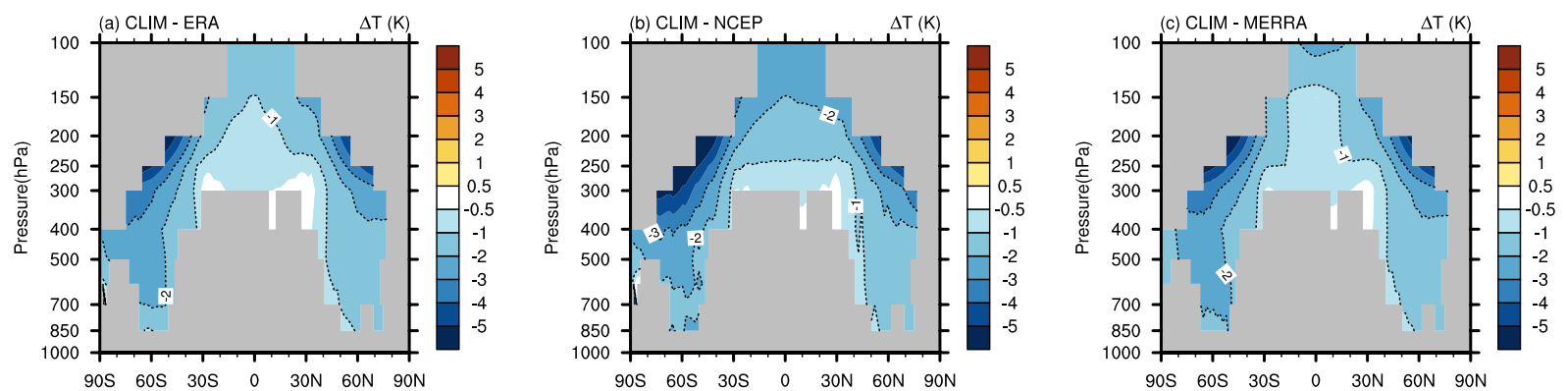

Figure 3. 5 yr (2006-2010) mean, zonally averaged differences between temperature simulated by the free-running CAM5 ("CLIM") and the (a) ERA-Interim (ECMWF Interim Reanalysis), (b) NCEP (National Centers for Environmental Prediction Reanalysis), (c) MERRA (Modern Era-Retrospective Analysis for Research and Applications). Units: K. Regions with mean ice crystal number concentration lower than $5 \mathrm{~g}^{-1}$ in the CLIM simulation are masked out in gray.
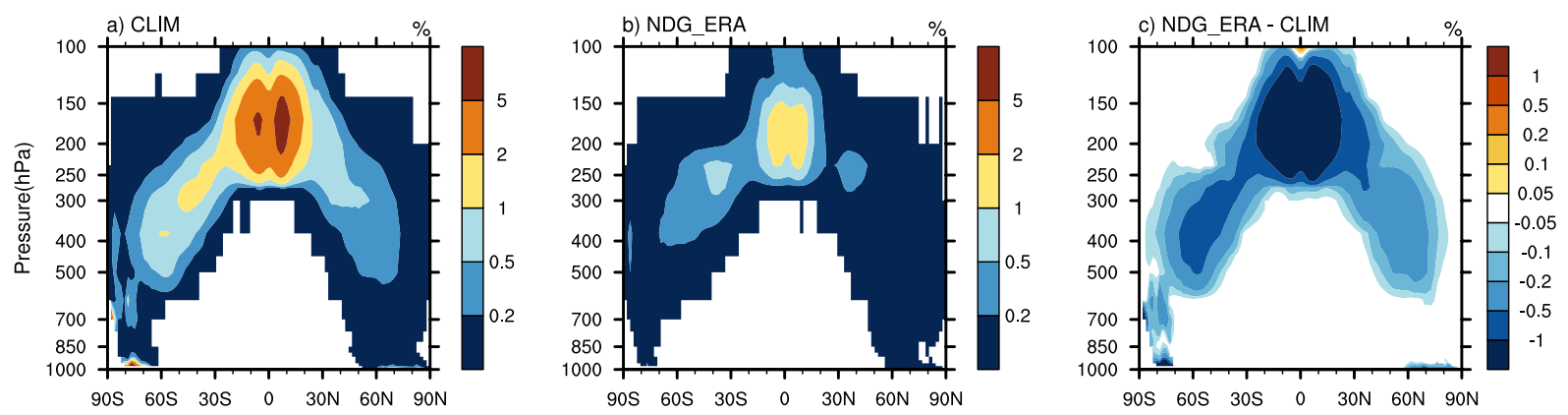

Figure 4. $5 \mathrm{yr}$ (2006-2010) mean, zonally averaged frequency of occurrence (unit: \%) of homogeneous ice nucleation in the (a) CAM5 CLIM and (b) NDG_ERA_UVT simulations, and (c) the differences. The frequency of occurrence was calculated using an online nucleation counter which keeps track whether there is homogeneous ice nucleation happening at each model time step. Both simulations used presentday (PD) aerosol emissions.

troposphere. Because homogeneous ice nucleation on sulfate is a main mechanism for aerosols to influence the LWCF in CAM5, the reduced nucleation frequency leads to deceases in $\triangle$ FLNT and $\triangle \mathrm{LWCF}$.

To verify the reasoning described above, a group of sensitivity simulations were conducted with weaker nudging for temperature. The results are shown in Fig. 5. As the relaxation time $\tau_{T}$ increases, the temperature climatology becomes closer to that in the free-running model (i.e., colder). More ice crystals are produced (Fig. 5a), and the PD-PI differences of LWCF increase (Fig. 5b). A trend of convergence with respect to $\tau_{T}$ can be seen in the results.

Although the simulations with varied $\tau_{T}$ confirm the relationship between temperature nudging and $\triangle \mathrm{LWCF}$, they do not verify whether the underlying mechanism is indeed the sensitivity of ice nucleation to ambient temperature. One could imagine, for example, that nudging temperature in the near surface levels might affect convection, and consequently the vertical transport of water vapor, which might affect humidity in the upper troposphere and hence the formation of ice clouds. To find out whether this is the case, we conducted additional simulations in which the temperature nudging was applied only to the lower or upper 15 layers of the model. The interface between layers 15 and 16 corresponds roughly to the $300 \mathrm{hPa}$ pressure level. In Fig. 6, the global mean uppertroposphere (100-300 hPa) ice crystal number concentration (Fig. 6a) and tropical $\left(20^{\circ} \mathrm{S}-20^{\circ} \mathrm{N}\right)$ mean convective precipitation rate (Fig. 6b) are shown as indices for ice formation and convective activity, respectively. Compared to the CLIM simulation, nudging temperature in the middle and lower troposphere leads to a substantial reduction of convective precipitation but no reduction in the ice crystal amount. In contrast, nudging the upper troposphere (NDG_ERA_UPPER) has a relatively small impact on convective precipitation, but strongly affects the ice crystal number concentration. Therefore the low ice crystal number concentration in the NDG_ERA_UVT simulation ("ALL" in Fig. 6) can not be explained by the changed convective transport of water vapor due to temperature nudging in the lower troposphere. Rather, it is mainly a response to changes in upper-troposphere temperature.

Having clarified the impact of temperature biases on ice cloud formation and ice-AIE in CAM5, ideally one should try to identify the cause of the biases then improve the model. This is, however, difficult to achieve in short term. Under the assumption that the temperature climatology in CAM5 will 

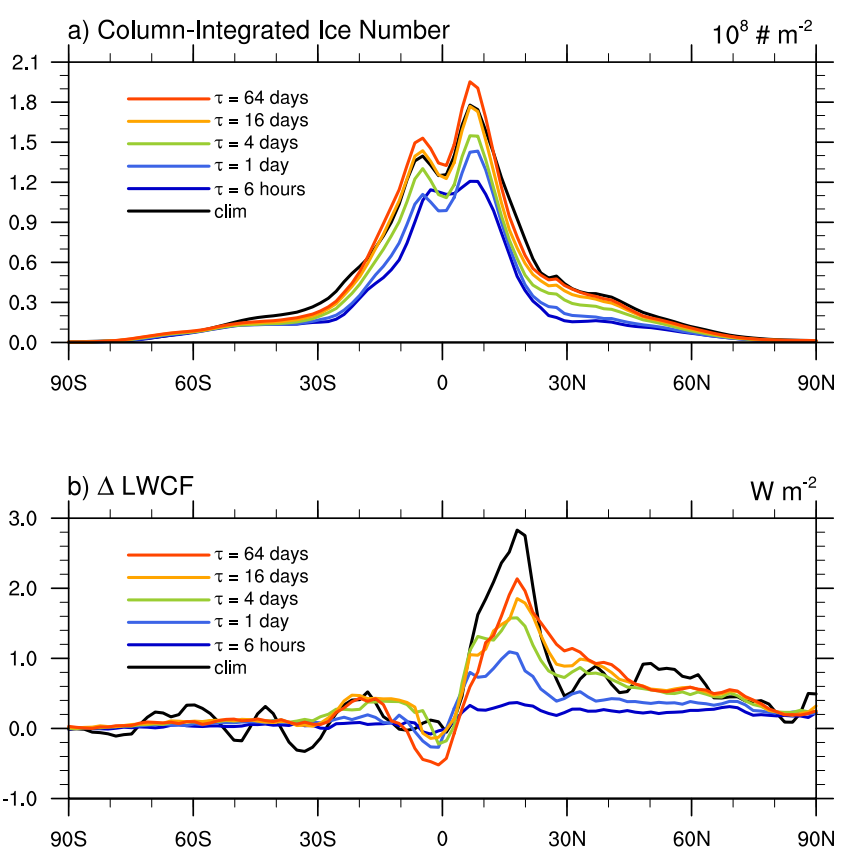

Figure 5. Sensitivity of zonal and annual mean (a) present-day ice crystal number concentration in the upper troposphere (vertical integral between $100 \mathrm{hPa}$ and $300 \mathrm{hPa}$, unit: $10^{8} \mathrm{~m}^{-2}$ ), and (b) aerosol induced long-wave cloud forcing change (PD-PI, unit: $\mathrm{W} \mathrm{m}^{-2}$ ), to the temperature relaxation time scale $\tau_{T}$ in CAM5 simulations where temperature and horizontal winds were nudged towards the ERA-Interim reanalysis.

stay unchanged until a major model upgrade, one needs to decide how to carry out the AeroCom ice-AIE experiments. For the purpose of evaluating and developing parameterizations for aerosols and ice clouds, using the observation constrained meteorology ensures that the parameterizations operates under "correct" meteorology. However, for the purpose of assessing the state of the art in global aerosol modeling, understanding uncertainties in the projected future climate change, and providing useful information for other applications of the same model, it is preferable for the nudged CAM5 simulations to retain the characteristics of the freerunning model. We therefore explored different experiment designs for the ice-AIE experiments.

\section{Alternative nudging strategies}

Since the temperature-nudging produces signatures that differ from the free-running CAM5 simulations, one might consider applying nudging to winds only, or use the anomaly nudging described in Sect. 2.2. In Fig. 7 the zonal and annual mean temperature simulated with the two methods are compared with the free-running CAM5 and the ERA reanalysis. As expected, the zonal mean temperature resulting from the anomaly nudging (NDG_ERA_UVTa) stays close to the unconstrained climatology (Fig. 7a), and is colder than reanal-
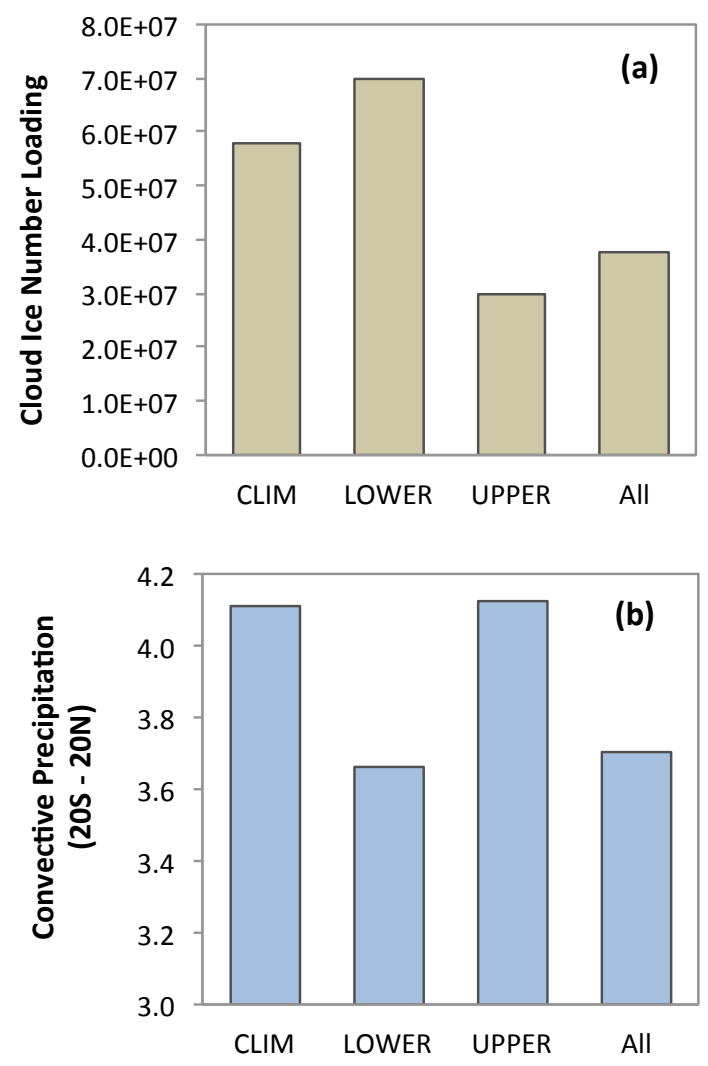

Figure 6. (a) Global mean cloud ice number loading between $100 \mathrm{hPa}$ and $300 \mathrm{hPa}$ (units: $\left.\mathrm{m}^{-2}\right)$, and (b) tropical $\left(20^{\circ} \mathrm{S}-20^{\circ} \mathrm{N}\right)$ mean convective precipitation rate $\left(\mathrm{mm} \mathrm{day}^{-1}\right)$, in various CAM5 simulations using present-day aerosol and precursor gas emissions. CLIM: without nudging; LOWER: temperature was nudged towards the ERA-Interim analysis in the lower 15 levels (roughly from $300 \mathrm{hPa}$ to the surface, NDG_ERA_LOWER in Table 1); UPPER: temperature was nudged towards the ERA-Interim analysis in the upper 15 levels (roughly from model top to $300 \mathrm{hPa}$, NDG_ERA_UPPER in Table 1); All: temperature on all model levels was nudged towards ERA-Interim (NDG_ERA_UVT in Table 1). In the latter three simulations, horizontal winds were nudged towards ERA-Interim on all levels. The nudging time scale, when applicable, was $6 \mathrm{~h}$. Details of the experimental setup are explained in Sect. 2.3 and Table 1.

ysis (Fig. 7b). The zonal mean temperature from the windonly nudging is closer to that of the CLIM simulation between $30^{\circ} \mathrm{S}$ and $30^{\circ} \mathrm{N}$, and is somewhere between the CLIM simulation and the reanalysis in the middle and high latitudes (Fig. 7d). The different behaviors in the low versus middle and high latitudes can be explained by the thermal wind relationship and the latitudinal variation of the Coriolis force.

Both the wind-only nudging and the anomaly nudging have potential issues. For the wind-only approach, a concern is that the inconsistency between mechanical and thermal forcing might induce spurious circulation. As for the anomaly nudging, the synoptic perturbations derived from the reanalysis might be inconsistent with the monthly mean 

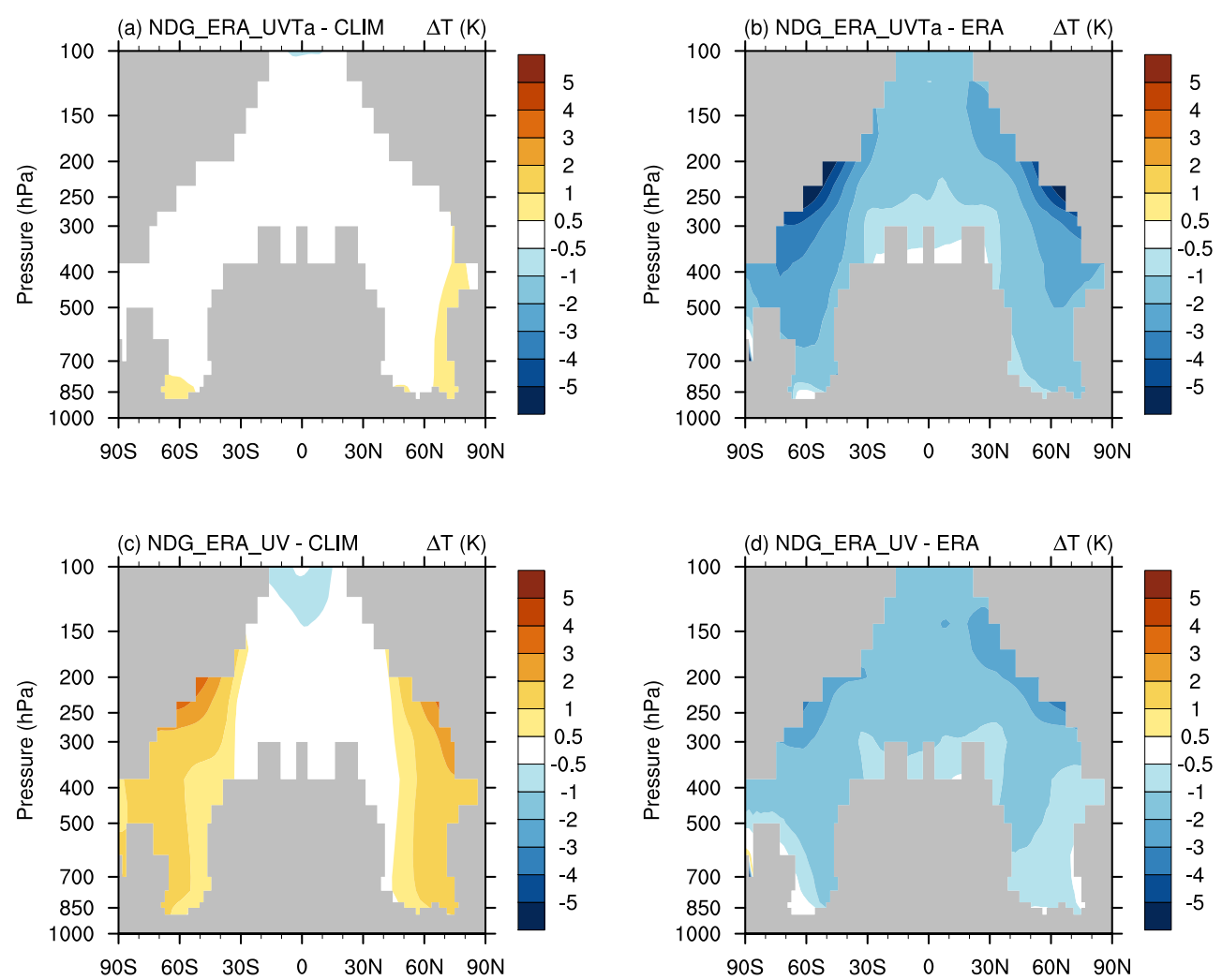

Figure 7. Left column: 5 yr (2006-2010) mean zonally averaged temperature differences between nudged and free-running CAM5 simulations. Right column: same as left column but between nudged CAM5 simulations and the ERA-Interim reanalysis. Simulations shown in the upper and lower rows used the anomaly nudging described in Sect. 2.2 (NDG_ERA_UVTa) and the wind-only nudging (NDG_ERA_UV), respectively. Like in Fig. 3, regions with mean ice crystal number concentration lower than $5 \mathrm{~g}^{-1}$ are masked out in gray.
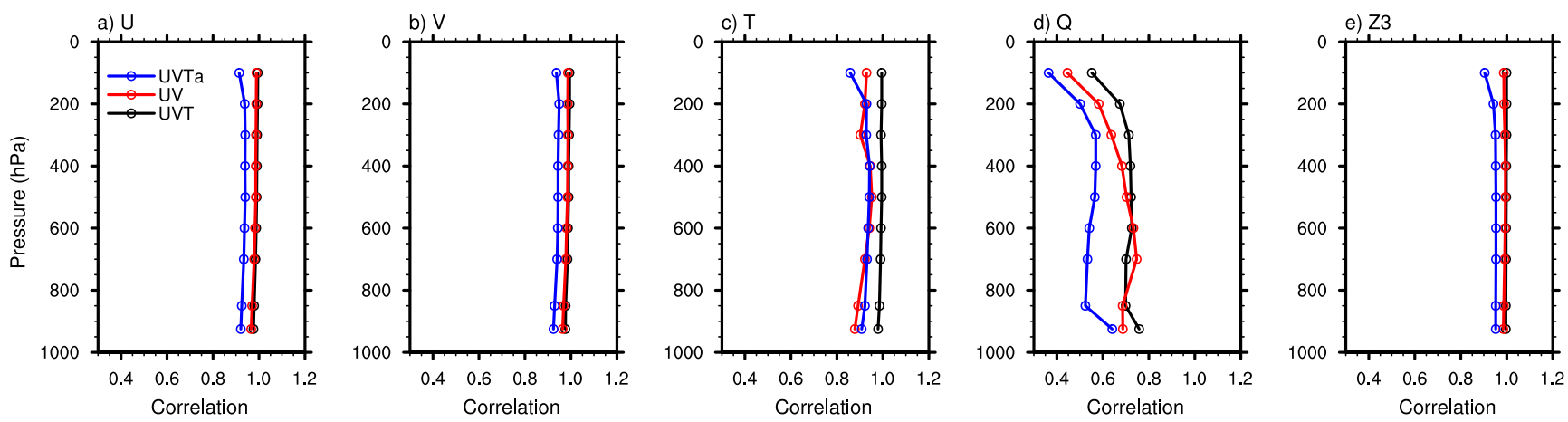

Figure 8. Anomaly correlation between the CAM5 simulated (a)-(b) horizontal winds (U and V), (c) temperature (T), (d) specific humidity (Q) and (e) geopotential height (Z3) and the ERA-Interim reanalysis. "UVT" is shorthand for NDG_ERA_UVT (the original method), "UV" for NDG_ERA_UV (wind-only nudging), and "UVTa" for NDG_ERA_UVTa (anomaly nudging). The correlation coefficients were computed from 6 hourly instantaneous data on pressure levels, with the corresponding monthly climatology removed.

climatology of the free-running model, thus also triggering spurious circulations. To evaluate the two methods in this regard, Fig. 8 compares the correlation between the simulated weather patterns with those in the reanalysis. For each variable and pressure level shown here, the correlation coefficient was computed from 6 hourly instantaneous data, with the corresponding monthly climatology removed. The orig- inal experimental design (NDG_ERA_UVT) is included as a reference. The year 2006 is presented here as an example. The same features have been seen in the other years (not shown).

On the whole, the wind and temperature anomalies in the nudged simulations agree quite well with those in the reanalysis, with correlation coefficients exceeding 0.9 on most 

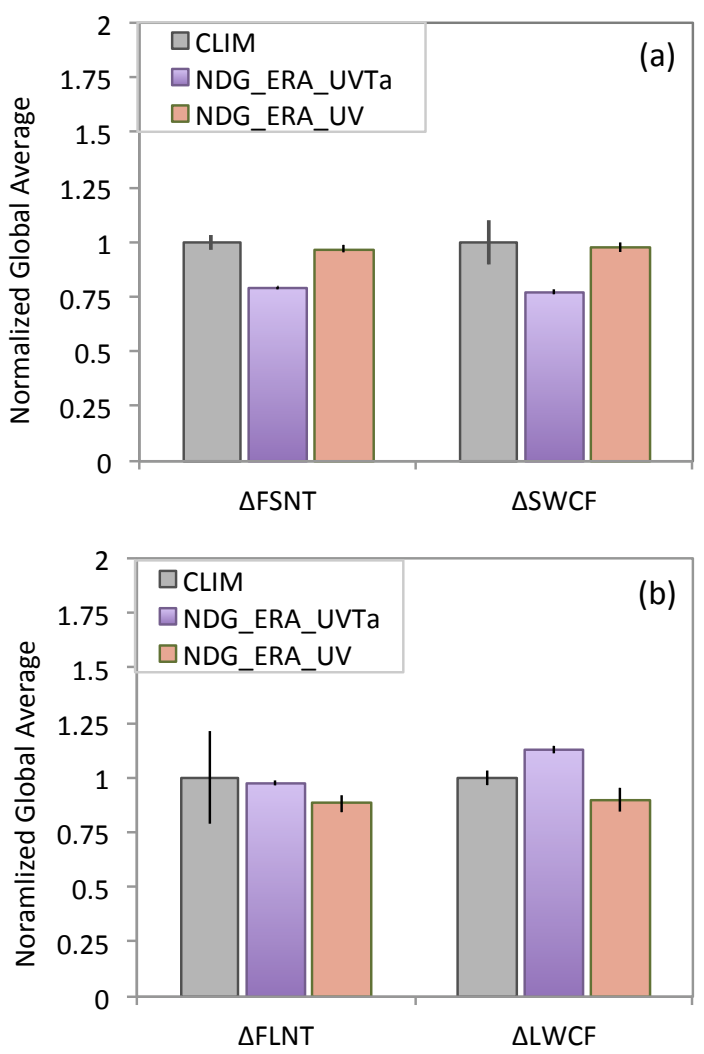

Figure 9. As in Fig. 2 but comparing two alternative nudging strategies (NDG_ERA_UVTa and NDG_ERA_UV) with the freerunning CAM5 model (CLIM).

vertical levels (Fig. 8a-c). The original method gives highest correlations for all three variables $(u, v, T)$. Between the two alternative approaches, the wind-only nudging results in slightly higher correlations for wind, and comparable results for temperature. These are understandable from the experimental design. For the geopotential height and specific humidity which are not directly constrained by the reanalysis, results obtained with wind-only nudging are better. This is especially true for humidity, possibly because the more realistic wind fields lead to better representation of the largescale transport of water vapor.

In Fig. 9 the aerosol-induced changes in TOA radiation fluxes and cloud forcing are presented for the alternative nudging strategies. Compared with the original method (NDG_ERA_UVT, green bars in Fig. 2), the results are substantially improved. This is especially true for the simulations using wind-only nudging, in which both the long-wave and shortwave fluxes agree within $15 \%$ with the references (CLIM). The anomaly nudging also produces signatures in aerosol forcing that are closer to the parent model, although the discrepancies with CLIM are slightly larger than those produced by the wind-only nudging. The PD-PI differences in FSNT and SWCF are about $25 \%$ smaller than in the freerunning model. Figures 8 and 9 and Tables A1 and A2 in- dicate that the wind-only nudging is able to provide wellconstrained model meteorology and meanwhile retain the original characteristics of the CAM5 climatology in terms of the TOA radiation budget and the hydrological cycle. It is also more convenient to apply in comparison with the anomaly nudging. Therefore, at least for carrying out the AeroCom ice-AIE experiments with CAM5, nudging the simulated horizontal winds but not temperature towards the ERAInterim reanalysis is our preferred experimental setup.

\section{Discussions}

Because the investigation presented above started from a model intercomparison activity and led to the preference of a different experimental design for CAM5, a question arose whether similar issues existed in other models. As a first attempt at answering the question, various sensitivity experiments were performed with the ECHAM6-HAM2 model (cf. Sect. 2.4). Considering that the simulation of aerosol indirect effect is associated with very high uncertainties (hence the need for model intercomparison), and that the two models (CAM5 and ECHAM6-HAM2) share very little in common in terms of model formulation, and have different biases, it is not expected that their responses to nudging will appear similar down to detailed (e.g. regional) levels. Rather, the aim here is to find out whether nudging has a strong impact on the ice-AIE in ECHAM6-HAM2 and whether the wind-only nudging is feasible in this model.

Our results show that although ECHAM6 also has systematic temperature biases whose magnitudes are affected by nudging, the estimated ice-AIE is rather insensitive to the experiment design. Using either the wind-and-temperature or wind-only nudging, the global mean PD-PI $\triangle$ LWCF agrees within $10 \%$ with the unconstrained estimate (Table A4). Considering that the default temperature relaxation time is longer in ECHAM6-HAM2 (24 h) than in CAM5 (6 h), we performed a series of simulations where $\tau_{T}$ was varied from $6 \mathrm{~h}$ to $64 \mathrm{~d}$, similar to the CAM5 experiments in Table 1 . The LWCF differences among these ECHAM6-HAM2 simulations turned out to be much smaller than those among the corresponding CAM5 simulations. Further analysis suggested that this lack of sensitivity to temperature nudging in ECHAM6-HAM2 is possibly attributable to the smaller (compared to CAM5) contribution of homogeneous nucleation to ice crystal number concentration (especially over the tropics), and the weaker sensitivity of ice formation to aerosol abundance in the parameterization of Kärcher and Lohmann (2002) and Lohmann and Kärcher (2002). At this point it is not clear which model is more realistic. Further investigations, including comparison with observations and fine-scale process modeling, may be helpful in this regard. As for the AercoCom intercomparison, in order to obtain a deeper understanding of the similarities and discrepancies among models, it will be useful to carry out detailed ice mass 
and number budget analyses to quantify the role of different processes in affecting the radiative properties of ice clouds.

One issue mentioned in Kooperman et al. (2012) and touched upon in Fig. $6 \mathrm{~b}$ is the impact of nudging on convection. In CAM5 the full (wind and temperature) nudging results in a decrease of global mean convective precipitation by about $16 \%$ (Table A1). A change of similar magnitude is seen in ECHAM6-HAM2, although with a different sign (i.e., increase by $17 \%$, cf. Table A3). In both models, constraining temperature also leads to changes in the liquid water path and SWCF in the low latitude regions. Mechanisms behind these sensitivities are not yet well understood, but it is clear that excluding temperature in the nudging gives better agreement with the unconstraint simulations (Tables A1-A4). The wind-only nudging thus appears beneficial for ECHAM6-HAM2 as well.

\section{Conclusions}

In this paper we discussed the impact of nudging on the characterization of aerosol indirect effects in two climate models. The motivation for using nudging in such an investigation is to allow for comparison with observations in a particular time period, to reduce uncertainties associated with natural variabilities in the large-scale flow, and to facilitate comparison among results from different models that participate in the AeroCom Phase III activities. However, the existence of systematic biases in the model can compromise the strategy because nudging introduces a forcing that attempts to correct the biases, hence changing the model's response to anthropogenic aerosols.

When nudging is allowed to remove the temperature biases in CAM5, the frequency of cloud ice formation decreases significantly in the upper troposphere. This leads to considerably smaller estimates of the anthropogenic aerosol impact on long-wave cloud forcing (LWCF), since homogeneous ice nucleation on sulfate is a main mechanism for aerosols to influence the LWCF in CAM5. Although simulations nudged towards the ERA-Interim reanalysis appear more realistic in some ways, process balances governing the model climate are no longer the same, making the results less useful for interpreting the behavior of the original model.

To resolve this issue, two alternative nudging approaches were tested. The first one applied nudging only to the horizontal winds from the ERA-Interim reanalysis, while the second method constrains both winds and temperature, but the reference meteorology was a combination of the climatology of CAM5 and the synoptic perturbations from the reanalysis. Evaluation indicated that in comparison with the original nudging strategy, the two methods led to substantially improved agreement with the free-running model in terms of the TOA radiation budget and cloud ice amount. Both methods were able to ensure high correlations between the simulated synoptic perturbations and those in the reanalysis. The wind- only nudging provided slightly more realistic results for the specific humidity and geopotential height, and led to estimates of the aerosol induced (PD-PI) cloud forcing changes that agreed better with those in the standard CAM5. It is also more convenient to apply than the anomaly nudging. We thus came to the conclusion that the wind-only nudging is a better strategy for the ice-AIE experiments for the CAM5 model.

Although the strong sensitivity of ice-AIE to temperature nudging is not seen in ECHAM6-HAM2, it may exist in other models that have systematic temperature bias and use ice cloud parameterizations that are sensitive to aerosol concentrations. Based on this consideration, a decision was made at the 12th AeroCom workshop (September 2013, Hamburg, Germany) that the phase III intercomparisons of aerosol indirect effects should use the wind-only nudging instead of the originally recommended wind-and-temperature nudging. Further analysis in our study indicated that in both CAM5 and ECHAM6-HAM2, in terms of liquid water path, shortwave cloud forcing and convective activities, the wind-only nudging produces results that agree better with the unconstrained simulations. This also supports the revision of experimental design for the AeroCom AIE intercomparisons.

More generally, we have shown that the forcing introduced by nudging towards reanalysis can be strong enough to significantly change the basic characteristics of the model climate, making the results less useful for the purpose of interpreting the behavior of the original model. The relaxation technique needs to be applied with care. Between wind and temperature nudging, the latter may cause more issues because there are a number of temperature and relative humidity thresholds related to the phase change of water and the onset of various microphysical processes. Mathematically, these thresholds correspond to discontinuities. Technically, they show up in conditional expressions in the models codes that lead to branching of the calculation. As a result, even a small change in temperature may lead to considerable differences in the simulated mean state and/or in the balance between processes. Wind nudging is less of a problem, except that it may affect the emissions of dust and sea salt (e.g. Timmreck and Schulz, 2004; Astitha et al., 2012) which are often parameterized with a threshold of the near-surface wind speed, or make a difference to the land/ocean surface process. Our results indicated that the wind-only nudging not only provides very good correlations (between model simulation and reanalysis) for the large-scale dynamical fields such as wind itself and geopotential height, but also indirectly improves the simulated specific humidity (possibly because of the large-scale transport). It thus seems a better choice to apply the wind-only nudging instead of the widely used windand-temperature nudging, at least for model intercomparison studies that focus on aerosol effects on cold clouds.

As an additional remark we note that nudging, and in a broader sense data assimilation, has been widely used in weather and climate related research and applications. Examples include initialization of weather forecast and climate 
prediction, boundary control and large-scale steering for downscaling using regional models, and parameter estimation (including reanalysis). The optimal assimilation strategy must be determined according to the specific needs of the application. For example for prediction and downscaling problems where the purpose of data assimilation is to keep the model state as close to the "truth" as possible (or in other words, to reduce model errors), constraining only the horizontal winds as discussed here may not be sufficient, especially if the model tends to generate large temperature biases. On the other hand, if the goal is to suppress the influence of natural variability and meanwhile let the model express its own characteristics (in other words, to expose model biases or inter-model discrepancies), like in the case of the AeroCom ice-AIE intercomparison, then our method can be a good option, and may potentially be used for regional modeling as well. In certain applications and regimes where wind differences between the driving data and the simulated values have significant impact on important features of the model results, or when the dynamical responses play an important role, one may need to loosen the constraint on winds as well, for example in certain geographical regions or in the nearsurface levels. Again, the optimal experimental design depends on the specific needs of the conceived application. 
Appendix A: Additional tables showing global mean climatology and aerosol effects in the unconstrained and nudged CAM5 and ECHAM6-HAM2 simulations

Table A1. Global mean metrics in free-running and nudged present-day simulations. Meanings of the acronyms are: SWCF: shortwave cloud forcing; LWCF: long-wave cloud forcing; CF: total cloud forcing; LWP: liquid water path; IWP: ice water path; PRECT: total precipitation rate; PRECL: large-scale precipitation rate; PRECC: convective precipitation rate; AOD: aerosol optical depth at $550 \mathrm{~nm}$ wavelength. All results are given as $5 \mathrm{yr}(2006-2010)$ average \pm one standard deviation of the annual mean.

\begin{tabular}{|c|c|c|c|c|c|c|c|c|c|}
\hline Simulation & $\begin{array}{c}\text { SWCF } \\
\left(\mathrm{W} \mathrm{m}^{-2}\right)\end{array}$ & $\begin{array}{c}\mathrm{LWCF} \\
\left(\mathrm{W} \mathrm{m}^{-2}\right)\end{array}$ & $\begin{array}{c}\mathrm{CF} \\
\left(\mathrm{W} \mathrm{m}^{-2}\right)\end{array}$ & $\begin{array}{c}\text { LWP } \\
\left(\mathrm{g} \mathrm{m}^{-2}\right)\end{array}$ & $\begin{array}{c}\text { IWP } \\
\left(\mathrm{g} \mathrm{m}^{-2}\right)\end{array}$ & $\begin{array}{c}\text { PRECT } \\
\left(\mathrm{mm} \mathrm{d}^{-1}\right)\end{array}$ & $\begin{array}{c}\text { PRECL } \\
\left(\mathrm{mm} \mathrm{d}^{-1}\right)\end{array}$ & $\begin{array}{c}\text { PRECC } \\
\left(\mathrm{mm} \mathrm{d}^{-1}\right)\end{array}$ & $\begin{array}{c}\text { AOD } \\
\text { (Unitless) }\end{array}$ \\
\hline CLIM & $-52.4 \pm 0.51$ & $23.9 \pm 0.06$ & $-28.5 \pm 0.54$ & $45.5 \pm 0.69$ & $17.6 \pm 0.10$ & $2.99 \pm 0.02$ & $0.88 \pm 0.005$ & $2.11 \pm 0.02$ & \\
\hline NDG_CLIM_UVT & $-51.8 \pm 0.48$ & $23.7 \pm 0.11$ & $-28.1 \pm 0.48$ & $45.2 \pm 0.83$ & $17.7 \pm 0$. & $3.00 \pm$ & $0.88 \pm 0.020$ & .02 & \\
\hline NDG_ERA_UVT & & & $-33.6 \pm 0.48$ & & & $2.66 \pm 0.02$ & & & \\
\hline NDG_ERA_UV & $-53.3 \pm 0.42$ & $24.4 \pm 0.22$ & $-28.8 \pm 0.60$ & $46.5 \pm 0.80$ & $17.3 \pm 0.19$ & $3.00 \pm 0.02$ & $0.89 \pm 0.015$ & $2.11 \pm 0.01$ & $0.122 \pm 0.002$ \\
\hline NDG_ERA_UVTa & $-50.7 \pm 0.29$ & $24.3 \pm 0.52$ & $-26.4 \pm 0.30$ & $42.5 \pm 0.26$ & $18.0 \pm 0.45$ & $2.87 \pm 0.04$ & $0.87 \pm 0.01$ & $1.99 \pm 0.05$ & $0.129 \pm 0.001$ \\
\hline
\end{tabular}

Table A2. As in Table A1 but for the aerosol induced changes (PD-PI differences, denoted by $\Delta$ ). FSNT, FLNT and FNET stand for the TOA net shortwave, long-wave and total radiation fluxes, respectively. Positive values denote downward fluxes. FLNTC is the clear-sky net long-wave flux. The other acronyms have the same meaning as in Table A1.

\begin{tabular}{|c|c|c|c|c|c|c|c|c|c|c|}
\hline Simulation & $\begin{array}{c}\Delta \text { FNET } \\
\left(\mathrm{W} \mathrm{m}^{-2}\right)\end{array}$ & $\begin{array}{c}\Delta \mathrm{FSNT} \\
\left(\mathrm{W} \mathrm{m}^{-2}\right)\end{array}$ & $\begin{array}{c}\Delta \text { FLNT } \\
\left(\mathrm{W} \mathrm{m}^{-2}\right)\end{array}$ & $\begin{array}{l}\triangle \text { FLNTC } \\
\left(\mathrm{W} \mathrm{m}^{-2}\right)\end{array}$ & $\begin{array}{l}\triangle \mathrm{SWCF} \\
\left(\mathrm{W} \mathrm{m}^{-2}\right)\end{array}$ & $\begin{array}{l}\triangle \mathrm{LWCF} \\
\left(\mathrm{W} \mathrm{m}^{-2}\right)\end{array}$ & $\begin{array}{c}\Delta C F \\
\left(\mathrm{~W} \mathrm{~m}^{-2}\right)\end{array}$ & $\begin{array}{c}\Delta \mathrm{LWP} \\
\left(\mathrm{g} \mathrm{m}^{-2}\right)\end{array}$ & $\begin{array}{c}\Delta \mathrm{IWP} \\
\left(\mathrm{g} \mathrm{m}^{-2}\right)\end{array}$ & $\begin{array}{c}\triangle \mathrm{AOD} \\
\text { (Unitless) }\end{array}$ \\
\hline CLIM & $-1.38 \pm 0.14$ & $-2.14 \pm 0.08$ & $0.76 \pm 0.16$ & $0.18 \pm 0.15$ & $-1.76 \pm 0.18$ & $0.58 \pm 0.02$ & $-1.27 \pm 0.12$ & $3.61 \pm 0.15$ & $0.17 \pm 0.05$ & $0.0148 \pm 0.0011$ \\
\hline NDG_CLIM_UVT & $-1.20 \pm 0.05$ & $-2.01 \pm 0.07$ & $0.80 \pm 0.06$ & $0.06 \pm 0.00$ & $-1.69 \pm 0.07$ & $0.80 \pm 0.06$ & $-0.94 \pm 0.05$ & $3.45 \pm 0.16$ & $0.35 \pm 0.03$ & $0.0155 \pm 0.0001$ \\
\hline NDG_ERA_UVT & $-1.48 \pm 0.04$ & $-1.70 \pm 0.03$ & $0.22 \pm 0.02$ & $0.07 \pm 0.01$ & $-1.33 \pm 0.03$ & $0.15 \pm 0.01$ & $-1.18 \pm 0.04$ & $3.70 \pm 0.12$ & $0.05 \pm 0.01$ & $0.0175 \pm 0.0001$ \\
\hline NDG_ERA_UV & $-1.40 \pm 0.06$ & $-2.07 \pm 0.04$ & $0.67 \pm 0.03$ & $0.15 \pm 0.01$ & $-1.72 \pm 0.04$ & $0.52 \pm 0.03$ & $-1.20 \pm 0.05$ & $3.50 \pm 0.09$ & $0.13 \pm 0.02$ & $0.0155 \pm 0.0002$ \\
\hline NDG_ERA_UVTa & $-1.05 \pm 0.03$ & $-1.90 \pm 0.02$ & $0.85 \pm 0.01$ & $0.08 \pm 0.01$ & $-1.58 \pm 0.02$ & $0.77 \pm 0.01$ & $-0.81 \pm 0.02$ & $3.01 \pm 0.04$ & $0.36 \pm 0.01$ & $0.0159 \pm 0.0002$ \\
\hline
\end{tabular}

Table A3. As in Table A1 but for ECHAM6-HAM2. CLIM refers to the unconstrained simulation. NDG_ERA_VDT is the configuration in which vorticity, divergence, surface pressure and temperature were nudged (cf. Sect. 2.4). NDG_ERA_VD is similar to NDG_ERA_VDT but without temperature nudging.

\begin{tabular}{|c|c|c|c|c|c|c|c|c|c|}
\hline Simulation & $\begin{array}{c}\mathrm{SWCF} \\
\left(\mathrm{W} \mathrm{m}^{-2}\right)\end{array}$ & $\begin{array}{c}\mathrm{LWCF} \\
\left(\mathrm{W} \mathrm{m}^{-2}\right)\end{array}$ & $\begin{array}{c}\mathrm{CF} \\
\left(\mathrm{W} \mathrm{m}^{-2}\right)\end{array}$ & $\begin{array}{c}\text { LWP } \\
\left(\mathrm{g} \mathrm{m}^{-2}\right)\end{array}$ & $\begin{array}{c}\text { IWP } \\
\left(\mathrm{g} \mathrm{m}^{-2}\right)\end{array}$ & $\begin{array}{c}\text { PRECT } \\
\left(\mathrm{mm} \mathrm{d}^{-1}\right)\end{array}$ & $\begin{array}{c}\text { PRECL } \\
\left(\mathrm{mm} \mathrm{d}^{-1}\right)\end{array}$ & $\begin{array}{c}\text { PRECC } \\
\left(\mathrm{mm} \mathrm{d}^{-1}\right)\end{array}$ & $\begin{array}{c}\text { AOD } \\
\text { (Unitless) }\end{array}$ \\
\hline CLIM & $-51.8 \pm 0.32$ & $27.0 \pm 0.11$ & $-24.9 \pm 0.37$ & $86.1 \pm 0.92$ & $10.3 \pm 0.04$ & $3.01 \pm 0.01$ & $1.59 \pm 0.02$ & $1.41 \pm 0.02$ & $0.126 \pm 0.002$ \\
\hline NDG_ERA_VDT & $-45.3 \pm 0.34$ & $24.2 \pm 0.12$ & $-21.1 \pm 0.37$ & $73.9 \pm 0.99$ & $10.5 \pm 0.06$ & $2.99 \pm 0.02$ & $1.34 \pm 0.03$ & $1.65 \pm 0.01$ & $0.121 \pm 0.003$ \\
\hline NDG_ERA_VD & $-49.8 \pm 0.29$ & $25.2 \pm 0.08$ & $-24.5 \pm 0.35$ & $83.4 \pm 1.03$ & $10.3 \pm 0.04$ & $3.01 \pm 0.02$ & $1.54 \pm 0.04$ & $1.47 \pm 0.02$ & $0.128 \pm 0.003$ \\
\hline
\end{tabular}

Table A4. As in Table A2 but for ECHAM6-HAM2. The simulation setups are explained in the caption of Table A3 and in Sect. 2.4.

\begin{tabular}{|c|c|c|c|c|c|c|c|c|c|c|}
\hline Simulation & $\begin{array}{c}\triangle \mathrm{FNET} \\
\left(\mathrm{W} \mathrm{m}^{-2}\right)\end{array}$ & $\begin{array}{c}\Delta \mathrm{FSNT} \\
\left(\mathrm{W} \mathrm{m}^{-2}\right)\end{array}$ & $\begin{array}{c}\Delta \text { FLNT } \\
\left(\mathrm{W} \mathrm{m}^{-2}\right)\end{array}$ & $\begin{array}{l}\triangle \text { FLNTC } \\
\left(\mathrm{W} \mathrm{m}^{-2}\right)\end{array}$ & $\begin{array}{l}\triangle \mathrm{SWCF} \\
\left(\mathrm{W} \mathrm{m}^{-2}\right)\end{array}$ & $\begin{array}{l}\Delta \mathrm{LWCF} \\
\left(\mathrm{W} \mathrm{m}^{-2}\right)\end{array}$ & $\begin{array}{c}\Delta \mathrm{CF} \\
\left(\mathrm{W} \mathrm{m}^{-2}\right)\end{array}$ & $\begin{array}{c}\Delta \mathrm{LWP} \\
\left(\mathrm{g} \mathrm{m}^{-2}\right)\end{array}$ & $\begin{array}{c}\Delta \mathrm{IWP} \\
\left(\mathrm{g} \mathrm{m}^{-2}\right)\end{array}$ & $\begin{array}{c}\triangle \mathrm{AOD} \\
\text { (Unitless) }\end{array}$ \\
\hline CLIM & $-1.46 \pm 0.33$ & $-2.11 \pm 0.25$ & $0.65 \pm 0.15$ & $-0.03 \pm 0.13$ & $-1.89 \pm 0.33$ & $0.67 \pm 0.19$ & $-1.21 \pm 0.37$ & $7.05 \pm 0.78$ & $0.19 \pm 0.04$ & $0.019 \pm 0.005$ \\
\hline NDG_ERA_VDT & $-1.19 \pm 0.06$ & $-1.84 \pm 0.04$ & $0.66 \pm 0.06$ & $-0.04 \pm 0.02$ & $-1.54 \pm 0.03$ & $0.70 \pm 0.04$ & $-0.84 \pm 0.04$ & $5.73 \pm 0.07$ & $0.21 \pm 0.01$ & $0.018 \pm 0.001$ \\
\hline NDG_ERA_VD & $-1.30 \pm 0.10$ & $-2.03 \pm 0.06$ & $0.73 \pm 0.08$ & $0.02 \pm 0.04$ & $-1.73 \pm 0.07$ & $0.71 \pm 0.05$ & $-1.02 \pm 0.08$ & $6.52 \pm 0.25$ & $0.21 \pm 0.02$ & $0.019 \pm 0.001$ \\
\hline
\end{tabular}


Acknowledgements. We thank Minghuai Wang, Heng Xiao, Yang Gao and Kyo-Sun Lim (PNNL) for helpful discussions. We also thank the two anonymous reviewers for their comments and suggestions. For the CAM5 simulations, computational resources (ark:/85065/d7wd3xhc) at the NCAR-Wyoming Supercomputing Center were provided by the National Science Foundation and the State of Wyoming, and supported by NCAR's Computational and Information Systems Laboratory. The PNNL Institutional Computing (PIC) also provided computational resources for short test simulations. K. Zhang, X. Liu, S. Ghan, P.-L. Ma, and P. J. Rasch were supported by the Office of Science of US Department of Energy as part of the Earth System Modeling Program and the Scientific Discovery Through Advanced Computing (SciDAC) Program. H. Wan was supported by the Linus Pauling Distinguished Postdoctoral Fellowship of the Pacific Northwest National Laboratory (PNNL) and the PNNL Laboratory Directed Research and Development Program. PNNL is a multiprogram laboratory operated for DOE by Battelle Memorial Institute under contract DE-AC05-76RL01830. G. J. Kooperman was supported by the Center for Multiscale Modeling of Atmospheric Processes (www.cmmap.org), a National Science Foundation, Science and Technology Center under Cooperative Agreement ATM-0425247, through sub-awards to Richard Somerville and John Helly. D. Neubauer gratefully acknowledges the support by the Austrian Science Fund (FWF): J 3402-N29 (Erwin Schrödinger Fellowship Abroad). The Center for Climate Systems Modeling (C2SM) at ETH Zurich is acknowledged for providing technical and scientific support.

Edited by: Y. Cheng

\section{References}

Astitha, M., Lelieveld, J., Abdel Kader, M., Pozzer, A., and de Meij, A.: Parameterization of dust emissions in the global atmospheric chemistry-climate model EMAC: impact of nudging and soil properties, Atmos. Chem. Phys., 12, 11057-11083, doi:10.5194/acp-12-11057-2012, 2012.

Bretherton, C. S. and Park, S.: A new moist turbulence parameterization in the Community Atmosphere Model, J. Climate, 22, 3422-3448, doi:10.1175/2008JCLI2556.1, 2009.

Brinkop, S. and Roeckner, E.: Sensitivity of a general circulationmodel to parameterizations of cloud-turbulence interactions inthe atmospheric boundary layer, Tellus A, 47, 197-220, 1995.

Coindreau, O., Hourdin, F., Haeffelin, M., Mathieu, A., and Rio, C.: Assessment of physical parameterizations using a global climate model with stretchable grid and nudging, Mon. Weather Rev., 135, 1474, doi:10.1175/MWR3338.1, 2007.

Dee, D. P., Uppala, S. M., Simmons, A. J., Berrisford, P., Poli, P., Kobayashi, S., Andrae, U., Balmaseda, M. A., Balsamo, G., Bauer, P., Bechtold, P., Beljaars, A. C. M., van de Berg, L., Bidlot, J., Bormann, N., Delsol, C., Dragani, R., Fuentes, M., Geer, A. J., Haimberger, L., Healy, S. B., Hersbach, H., Hólm, E. V., Isaksen, L., Kållberg, P., Köhler, M., Matricardi, M., McNally, A. P., Monge-Sanz, B. M., Morcrette, J.-J., Park, B.K., Peubey, C., de Rosnay, P., Tavolato, C., Thépaut, J.-N., and Vitart, F.: The ERA-Interim reanalysis: configuration and perfor- mance of the data assimilation system, Q. J. Roy. Meteor. Soc., 137, 553-597, doi:10.1002/qj.828, doi:10.1002/qj.828, 2011.

Dentener, F., Feichter, J., and Jeuken, A.: Simulation of the transport of $\mathrm{Rn}^{222}$ using on-line and off-line global models at different horizontal resolutions: a detailed comparison with measurements, Tellus B, 51, 573, doi:10.1034/j.1600-0889.1999.t01-200001.x, 1999.

Feichter, J. and Lohmann, U.: Can a relaxation technique be used to validate clouds and sulphur species in a GCM?, Q. J. Roy. Meteor. Soc., 125, 1277-1294, doi:10.1002/qj.1999.49712555609, 1999.

Gates, W. L., Boyle, J., Covey, C., Dease, C., Doutriaux, C., Drach, R., Fiorino, M., Gleckler, P., Hnilo, J., Marlais, S., Phillips, T., Potter, G., Santer, B., Sperber, K., Taylor, K., and Williams, D.: An overview of the results of the Atmospheric Model Intercomparison Project (AMIP I), B. Am. Meteorol. Soc., 80, 29-55, doi:10.1175/15200477(1999)080<0029:AOOTRO>2.0.CO;2, 1999.

Gettelman, A., Morrison, H., and Ghan, S. J.: A new twomoment bulk stratiform cloud microphysics scheme in the Community Atmosphere Model, Version 3 (CAM3). Part II: Single-column and global results, J. Climate, 21, 3660-3679, doi:10.1175/2008JCLI2116.1, 2008.

Gettelman, A., Liu, X., Ghan, S. J., Morrison, H., Park, S., Conley, A. J., Klein, S. A., Boyle, J., Mitchell, D. L., and Li, J.-F. L.: Global simulations of ice nucleation and ice supersaturation with an improved cloud scheme in the Community Atmosphere Model, J. Geophys. Res., 115, D18216, doi:10.1029/2009JD013797, 2010.

Ghan, S., Laulainen, N., Easter, R., Wagener, R., Nemesure, S., Chapman, E., Zhang, Y., and Leung, R.: Evaluation of aerosol direct radiative forcing in MIRAGE, J. Geophys. Res., 106, 52955316, doi:10.1029/2000JD900502, 2001.

Giorgetta, M. A., Roeckner, E., Mauritsen, T., Bader, B. S. J., Crueger, T., Esch, M., Rast, S., Schmidt, L. K. H., Kinne, S., Möbis, B., and Krismer, T.: The Atmospheric General Circulation Model ECHAM6: Model Description, Tech. rep., ISSN 1614-1199, Max Planck Institute for Meteorology, Hamburg, Germany, 2012.

Hauglustaine, D. A., Hourdin, F., Jourdain, L., Filiberti, M. A., Walters, S., Lamarque, J. F., and Holland, E. A.: Interactive chemistry in the Laboratoire de Meteorologie Dynamique general circulation model, J. Geophys. Res., 109, D04314, doi:10.1029/2003JD003957, 2004.

Iacono, M. J., Delamere, J. S., Mlawer, E. J., Shephard, M. W., Clough, S. A., and Collins, W. D.: Radiative forcing by long-lived greenhouse gases: calculations with the AER radiative transfer models, J. Geophys. Res.-Atmos., 113, D13103, doi:10.1029/2008JD009944, 2008.

Jeuken, A. B. M., Siegmund, P. C., Heijboer, L. C., Feichter, J., and Bengtsson, L.: On the potential of assimilating meteorological analyses in a global climate model for the purpose of model validation, J. Geophys. Res., 101, 16939-16950, doi:10.1029/96JD01218, 1996.

Jöckel, P., Kerkweg, A., Pozzer, A., Sander, R., Tost, H., Riede, H., Baumgaertner, A., Gromov, S., and Kern, B.: Development cycle 2 of the Modular Earth Submodel System (MESSy2), Geosci. Model Dev., 3, 717-752, doi:10.5194/gmd-3-717-2010, 2010. 
Kanamitsu, M., Ebisuzaki, W., Woollen, J., Yang, S.-K., Hnilo, J. J., Fiorino, M., and Potter, G. L.: NCEP-DOE AMIP-II Reanalysis (R-2)., B. Am. Meteorol. Soc., 83, 1631-1643, doi:10.1175/BAMS-83-11-1631, 2002.

Kärcher, B. and Lohmann, U.:, A Parameterization of cirrus cloud formation: Homogeneous freezing including effects of aerosol size, J. Geophys. Res., 107, 4698, doi:10.1029/2001JD001429, 2002.

Kerkweg, A., Sander, R., Tost, H., and Jöckel, P.: Technical note: Implementation of prescribed (OFFLEM), calculated (ONLEM), and pseudo-emissions (TNUDGE) of chemical species in the Modular Earth Submodel System (MESSy), Atmos. Chem. Phys., 6, 3603-3609, doi:10.5194/acp-6-3603-2006, 2006.

Kooperman, G. J., Pritchard, M. S., Ghan, S. J., Wang, M., Somerville, R. C. J., and Russell, L. M.: Constraining the influence of natural variability to improve estimates of global aerosol indirect effects in a nudged version of the Community Atmosphere Model 5, J. Geophys. Res., 117, D23204, doi:10.1029/2012JD018588, 2012.

Lamarque, J.-F., Bond, T. C., Eyring, V., Granier, C., Heil, A., Klimont, Z., Lee, D., Liousse, C., Mieville, A., Owen, B., Schultz, M. G., Shindell, D., Smith, S. J., Stehfest, E., Van Aardenne, J., Cooper, O. R., Kainuma, M., Mahowald, N., McConnell, J. R., Naik, V., Riahi, K., and van Vuuren, D. P.: Historical (1850-2000) gridded anthropogenic and biomass burning emissions of reactive gases and aerosols: methodology and application, Atmos. Chem. Phys., 10, 7017-7039, doi:10.5194/acp10-7017-2010, 2010.

Lim, K.-S. S., Fan, J., Leung, L. R., Ma, P.-L., Singh, B., Zhao, C., Zhang, Y., Zhang, G., and Song, X.: Investigation of aerosol indirect effects using a cumulus microphysics parameterization in a regional climate model, J. Geophys. Res.-Atmos., 119, 906-926, doi:10.1002/2013JD020958, 2014.

Lin, S.-J.: A "Vertically Lagrangian" finite-volume dynamical core for global models, Mon. Weather Rev., 132, 2293-2307, doi:10.1175/1520-0493(2004)132<2293:AVLFDC>2.0.CO;2, 2004.

Lin, S.-J. and Rood, R. B.: Multidimensional flux-form semi-Lagrangian transport schemes, Mon. Weather Rev., 124, 2046-2070, doi:http://dx.doi.org/10.1175/15200493(1996)124<2046:MFFSLT>2.0.CO;2, 1996.

Liu, X. and Penner, J.: Ice nucleation parameterization for a global model, Meteorol. Z., 14, 499-514, doi:10.1127/09412948/2005/0059, 2005.

Liu, X., Easter, R. C., Ghan, S. J., Zaveri, R., Rasch, P., Shi, X., Lamarque, J.-F., Gettelman, A., Morrison, H., Vitt, F., Conley, A., Park, S., Neale, R., Hannay, C., Ekman, A. M. L., Hess, P., Mahowald, N., Collins, W., Iacono, M. J., Bretherton, C. S., Flanner, M. G., and Mitchell, D.: Toward a minimal representation of aerosols in climate models: description and evaluation in the Community Atmosphere Model CAM5, Geosci. Model Dev., 5, 709-739, doi:10.5194/gmd-5-709-2012, 2012.

Liu, X. H., Penner, J. E., Ghan, S. J., and Wang, M. H.: Inclusion of ice microphysics in the NCAR community atmospheric model version 3 (CAM3), J. Climate, 20, 4526-4547, doi:10.1175/JCLI4264.1, 2007.

Lohmann, U. and Ferrachat, S.: Impact of parametric uncertainties on the present-day climate and on the anthropogenic aerosol ef- fect, Atmos. Chem. Phys., 10, 11373-11383, doi:10.5194/acp10-11373-2010, 2010.

Lohmann, U. and Hoose, C.: Sensitivity studies of different aerosol indirect effects in mixed-phase clouds, Atmos. Chem. Phys., 9, 8917-8934, doi:10.5194/acp-9-8917-2009, 2009.

Lohmann, U., Stier, P., Hoose, C., Ferrachat, S., Kloster, S., Roeckner, E., and Zhang, J.: Cloud microphysics and aerosol indirect effects in the global climate model ECHAM5-HAM, Atmos. Chem. Phys., 7, 3425-3446, doi:10.5194/acp-7-3425-2007, 2007.

Lohmann, U., and Kärcher B.: First interactive simulations of cirrus clouds formed by homogeneous freezing in the ECHAM general circulation model, J. Geophys. Res., 107, 4105, doi:10.1029/2001JD000767, 2002.

Ma, P.-L., Rasch, P. J., Fast, J. D., Easter, R. C., Gustafson Jr., W. I., Liu, X., Ghan, S. J., and Singh, B.: Assessing the CAM5 physics suite in the WRF-Chem model: implementation, resolution sensitivity, and a first evaluation for a regional case study, Geosci. Model Dev., 7, 755-778 doi:10.5194/gmd-7-755-2014, 2014.

Machenhauer, B. and Kirchner, I.: Diagnosis of systematic initial tendency errors in the ECHAM AGCM using slow normal mode data assimilation of ECMWF reanalysis data, CLIVAR Exchanges, 5, 9-10, available at: http://web.dmi.dk/pub/ POTENTIALS/Final/Appendix-1.PDF (last access: April 2014), 2000.

Mlawer, E. J., Taubman, S. J., Brown, P. D., Iacono, M. J., and Clough, S. A.: Radiative transfer for inhomogeneous atmospheres: RRTM, a validated correlated-k model for the longwave., J. Geophys. Res., 102, 16663-16682, doi:10.1029/97JD00237, 1997.

Morrison, H. and Gettelman, A.: A new two-moment bulk stratiform cloud microphysics scheme in the NCAR Community Atmosphere Model (CAM3), Part I: Description and numerical tests, J. Climate, 21, 3642-3659, doi:10.1175/2008JCLI2105.1, 2008.

Neale, R. B., Chen, C. C., Gettelman, A., Lauritzen, P. H., Park, S., Williamson, D. L., Conley, A. J., Garcia, R., Kinnison, D., Lamarque, J. F., Marsh, D., Mills, M., Smith, A. K., Tilmes, S., Vitt, F., Morrison, H., Cameron-Smith, P., Collins, W. D., Iacono, M. J., Easter, R. C., Ghan, S. J., Liu, X. H., Rasch, P. J., and Taylor, M. A.: Description of the NCAR Community Atmosphere Model (CAM5.0), Tech. Rep. NCAR/TN-486-STR, NCAR, available at: http://www.cesm.ucar.edu/models/cesm1.0/ cam/ (last access: April 2014), 2010.

Nordeng, T. E.: Extended versions of the convective parametrization scheme at ECMWF and their impact on the mean and transient activity of the model in the tropics, ECMWF Research Department, Technical Momorandum 206, European Centre for Medium-range Weather Forecast, Reading, UK, Reading, UK, 1994.

Park, S. and Bretherton, C. S.: The University of Washington shallow convection and moist turbulence schemes and their impact on climate simulations with the Community Atmosphere Model, J. Climate, 22, 3449-3469, doi:10.1175/2008JCLI2557.1, 2009.

Rienecker, M. M., Suarez, M. J., Gelaro, R., Todling, R., Bacmeister, J., Liu, E., Bosilovich, M. G., Schubert, S. D., Takacs, L., Kim, G.-K., Bloom, S., Chen, J., Collins, D., Conaty, A., da Silva, A., Gu, W., Joiner, J., Koster, R. D., Lucchesi, R., 
Molod, A., Owens, T., Pawson, S., Pegion, P., Redder, C. R., Reichle, R., Robertson, F. R., Ruddick, A. G., Sienkiewicz, M., and Woollen, J.: MERRA: NASA's modern-era retrospective analysis for research and applications, J. Climate, 24, 3624-3648, doi:10.1175/JCLI-D-11-00015.1, 2011.

Roelofs, G.-J., ten Brink, H., Kiendler-Scharr, A., de Leeuw, G., Mensah, A., Minikin, A., and Otjes, R.: Evaluation of simulated aerosol properties with the aerosol-climate model ECHAM5HAM using observations from the IMPACT field campaign, Atmos. Chem. Phys., 10, 7709-7722, doi:10.5194/acp-10-77092010, 2010.

Schmidt, G. A., Ruedy, R., Hansen, J. E., Aleinov, I., Bell, N., Bauer, M., Bauer, S., Cairns, B., Canuto, V., Cheng, Y., Del Genio, A., Faluvegi, G., Friend, A. D., Hall, T. M., Hu, Y. Y., Kelley, M., Kiang, N. Y., Koch, D., Lacis, A. A., Lerner, J., Lo, K. K., Miller, R. L., Nazarenko, L., Oinas, V., Perlwitz, J., Rind, D., Romanou, A., Russell, G. L., Sato, M., Shindell, D. T., Stone, P. H., Sun, S., Tausnev, N., Thresher, D., and Yao, M. S.: Presentday atmospheric simulations using GISS ModelE: comparison to in situ, satellite, and reanalysis data, J. Climate, 19, 153-192, doi:10.1175/JCLI3612.1, 2006.

Schulz, M., Cozic, A., and Szopa, S.: LMDzT-INCA dust forecast model developments and associated validation efforts, IOP C. Ser. Earth Env., 7, 012014, doi:10.1088/1755-1307/7/1/012014, 2009.

Simmons, A. J., Burridge, D. M., Jarraud, M., Girard, C., and Wergen, W.: The ECMWF medium-range prediction models development of the numerical formulations and the impact of increased resolution, Meteorol. Atmos. Phys., 40, 28-60, doi:10.1007\%2FBF01027467, 1989.

Song, X. and Zhang, G. J.: Microphysics parameterization for convective clouds in a global climate model: description and singlecolumn model tests, J. Geophys. Res.-Atmos., 116, D02201, doi:10.1029/2010JD014833, 2011.

Song, X., Zhang, G. J., and Li, J.-L. F.: Evaluation of microphysics parameterization for convective clouds in the NCAR Community Atmosphere Model CAM5, J. Climate, 25, 85688590, doi:10.1175/JCLI-D-11-00563.1, 2012.
Stevens, B., Giorgetta, M. A., Esch, M., Mauritsen, T., Crueger, T., Rast, S., Salzmann, M., Schmidt, H., Bader, J., Block, K. and Brokopf, R., Fast, I., Kinne, S., Kornblueh, L., Lohmann, U., Pincus, R., Reichler, T. and Roeckner, E.: Atmospheric component of the MPI-M Earth System Model: ECHAM6, J. Adv. Model. Earth Syst., 5, 1942-2466, doi:10.1002/jame.20015, 2013.

Stier, P., Feichter, J., Kinne, S., Kloster, S., Vignati, E., Wilson, J., Ganzeveld, L., Tegen, I., Werner, M., Balkanski, Y., Schulz, M., Boucher, O., Minikin, A., and Petzold, A.: The aerosol-climate model ECHAM5-HAM, Atmos. Chem. Phys., 5, 1125-1156, doi:10.5194/acp-5-1125-2005, 2005.

Telford, P. J., Braesicke, P., Morgenstern, O., and Pyle, J. A.: Technical Note: Description and assessment of a nudged version of the new dynamics Unified Model, Atmos. Chem. Phys., 8, 17011712, doi:10.5194/acp-8-1701-2008, 2008.

Tiedtke, M.: A comprehensive mass flux scheme for cumulus parameterization in large scale models, Mon. Weather Rev., 117, 1779-1800, doi:http://dx.doi.org/10.1175/15200493(1989)117<1779:ACMFSF>2.0.CO;2,1989.

Timmreck, C. and Schulz, M.: Significant dust simulation differences in nudged and climatological operation mode of the AGCM ECHAM, J. Geophys. Res., 109, D13202, doi:10.1029/2003JD004381, 2004.

van Aalst, M. K., van den Broek, M. M. P., Bregman, A., Brühl, C., Steil, B., Toon, G. C., Garcelon, S., Hansford, G. M., Jones, R. L., Gardiner, T. D., Roelofs, G. J., Lelieveld, J., and Crutzen, P.J.: Trace gas transport in the 1999/2000 Arctic winter: comparison of nudged GCM runs with observations, Atmos. Chem. Phys., 4, 81-93, doi:10.5194/acp-4-81-2004, 2004.

Zhang, G. J. and McFarlane, N. A.: Sensitivity of climate simulations to the parameterization of cumulus convection in the Canadian Climate Centre general circulation model, Atmos. Ocean, 33, 407-446, doi:10.1080/07055900.1995.9649539, 1995.

Zhang, K., O’Donnell, D., Kazil, J., Stier, P., Kinne, S., Lohmann, U., Ferrachat, S., Croft, B., Quaas, J., Wan, H., Rast, S., and Feichter, J.: The global aerosol-climate model ECHAM-HAM, version 2: sensitivity to improvements in process representations, Atmos. Chem. Phys., 12, 8911-8949, doi:10.5194/acp-12-8911-2012, 2012. 